\title{
Removal of Volatile Organic Compounds (VOCs) on synthesized zeolites
}

\author{
$\underline{\text { Roman Petrus }}^{1}$, Jolanta Warchoł ${ }^{2}$, Waldemar Prokop ${ }^{3}$, Magdalena Warzybok ${ }^{3}$ \\ 1. The Faculty of Chemistry, Rzeszów University of Technology, POLAND, Rzeszów, al. Powstańców Warszawy \\ 6, 35-959 Rzeszów, E-mail: ichrp@prz.edu.pl \\ 2. The Faculty of Chemistry, Wrocław University of Science and Technology, POLAND, Wrocław, Wybrzeże \\ Wyspiańskiego 27, 50-370 Wrocław, E-mail: jolanta.warchol@pwr.edu.pl \\ 3. OTTO Engineering Polska Sp. z o.o., POLAND, Rzeszów, ul. Połonińska 15, 35-082 Rzeszów, E-mail: \\ waldemar.prokop@ottoindustries.com.pl
}

Abstract - The aim of this study was synthesis of Y-zeolite by recrystallization of natural clay materials, its application to adsorption of selected carbonyl compounds and modelling the adsorption equilibria and dynamics. High adsorption capacity and the possibility of using synthesized zeolite as a filling of zeolite rotors were demonstrated.

Keywords - synthetic zeolites, volatile organic compounds, acetone, methyl ethyl ketone, adsorption

\section{Introduction}

Volatile Organic Compounds (VOCs) are substances, which presence in the environment contributes to formation of ozone, which in turn favors the formation of photochemical smog and secondary pollutants in the form of organic aerosols. Sources of VOC emissions to the atmosphere are primarily emissions of fumes, evaporation of fuels and solvents, and biomass combustion [1]. The commonly used method of VOC emission reduction is adsorption on active carbon. However, due to the hygroscopicity and flammability of coal, alternative adsorbents are sought. Among which we can distinguish synthetic zeolites, which are characterized by high adsorption capacity and thermostability, which enables thermal regeneration at temperatures above $200^{\circ} \mathrm{C}$ and their multiple use.

\section{Zeolite synthesis}

Zeolite was prepared by indirect synthesis including recrystallization of natural clay material. The synthesis process consisted of three stages, activation of the clay material, as well as ageing and crystallization of the reaction mixture. Three clay materials, kaolinite, bentonite and halloysite were selected for the study. The influence of clay material type, temperature and time of subsequent stages of synthesis on the process efficiency was investigated. The selected synthesis product was subjected to instrumental analysis.

\section{VOC adsorption}

Adsorption of acetone, MEK (methyl ethyl ketone) and acetone/MEK mixture in a specially prepared installation was carried out. The values of equilibrium concentration in the constant phase $\left(q_{\mathrm{e}}\right)$ were calculated using the numerical integration method. It was shown that the Y-type zeolite obtained had at least comparable adsorption capacity to carbonyl compounds in comparison with commercially used adsorbents (zeolite X13, active carbon).

\section{Modelling the adsorption equilibrium}

Isotherms of acetone and MEK adsorption on Y-zeolite were determined and then the process dynamics was calculated. The approximation accuracy of experimental and model value of the maximum adsorption capacity $\left(q_{m}\right)$ was chosen to evaluate the quality of model matching. Its adoption as a selection criterion enabled to indicate Langmuir and Langmuir-Freundlich models as the most adequate to the mathematical description of adsorption equilibrium.

\section{Simulation of the concentration profiles distribution}

The parameters $K, q_{\mathrm{m}}$ and $n$, determined during modelling of equilibrium, were used to simulate the distribution of concentrations in the adsorption column filled with zeolite. The 
Equilibrium-Dispersion model (R-D) was used to model the adsorption dynamics of single component systems:

$$
\left[\left(1+\left(\frac{1-\varepsilon_{\mathrm{t}}}{\varepsilon_{\mathrm{t}}} \cdot \rho_{\mathrm{s}}\right) \cdot\left(\frac{\partial q_{\mathrm{i}}}{\partial C_{\mathrm{i}}}\right)\right) \frac{\partial C_{\mathrm{i}}}{\partial t}\right]+\left(\frac{u}{\varepsilon_{\mathrm{t}}}\right) \cdot\left(\frac{\partial C_{\mathrm{i}}}{\partial l}\right)=D_{a} \frac{\partial^{2} C_{\mathrm{i}}}{\partial l^{2}}
$$

The following Danckwert's boundary conditions were maintained:

for $t>0 ; l=0$ :

$$
u \cdot\left[C_{0, i}(t)-C_{\mathrm{i}}(t, 0)\right]=-\varepsilon_{\mathrm{t}} \cdot D_{\mathrm{a}} \cdot \frac{\partial C_{\mathrm{i}}(t, 0)}{\partial l}
$$

for $t>0 ; l=L$ :

$$
\frac{\partial C_{i}(t, L)}{\partial l}=0
$$

where: $C_{\mathrm{i}}$ and $q_{\mathrm{i}}$ - concentration in the mobile phase $\left[\mathrm{mmol} / \mathrm{cm}^{3}\right]$ and on the adsorbent surface $[\mathrm{mmol} / \mathrm{g}], t$ - duration of the process $[\mathrm{s}], l$ - distance counted from the beginning of column [cm], $D_{\mathrm{a}}-$ effective dispersion coefficient $\left[\mathrm{cm}^{2} / \mathrm{s}\right], \varepsilon_{\mathrm{t}}-$ total porosity [-], $\rho_{\mathrm{s}}-$ specific density of adsorbent grain $\left[\mathrm{g} / \mathrm{cm}^{3}\right], u$ - velocity counted per empty cross-section of column $[\mathrm{cm} / \mathrm{s}], L-$ column length $[\mathrm{cm}], C_{0, i}-$ inlet concentration of $i$ component $\left[\mathrm{g} / \mathrm{cm}^{3}\right]$.

As a result of supplementing R-D model with Langmuir-Freundlich equation and estimation of the heterogeneity parameter $n$, the exact coverage of experimental points in singlecomponent systems was obtained (Fig. 1A). For the two-component system (acetone, MEK) calculations were performed using two models, R-D or Kinetic-Dispersion (K-D), supplemented with the extended Langmuir equation. The calculations showed a need to search for values of all parameters ( $k, K$ and $\left.q_{m}\right)$ (Fig. 1B).
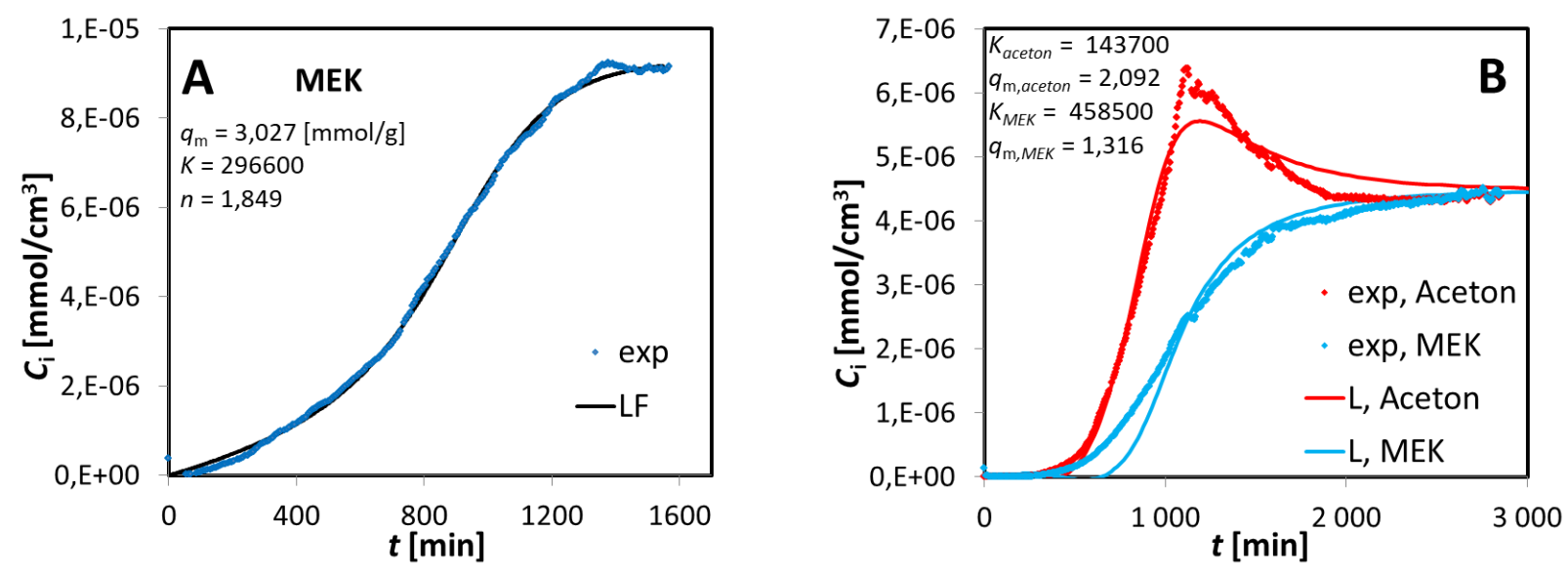

Fig. 1. Modelling of concentration profiles (A) of MEK and (B) acetone/MEK mixture in the column filled with synthesized zeolite. Simulation with R-D model.

\section{Acknowledgments}

The adsorption analysis was performed at OTTO Engineering Polska Sp. z o.o.

\section{References}

[1] N. Ramirez, A. Cuadras, E. Rovira, F. Borrull, R.M. Marce, "Chronic risk assessment of exposure to volatile organic compounds in the atmosphere near the largest Mediterranean industrial site," Environmental International, vol. 39, no. 1, February, pp. 200-209, year. 2012. 